\title{
Anestesia para insuficiência respiratória restritiva
}

\section{Anaesthesia in restricitive respiratory insufficiency}

\section{Cláudia Lütke}

Escola Paulista de Medicina / Universidade Federal de São Paulo - UNIFESP.

Sendo a respiração - em definição simplista - a adequada captação de oxigênio e a correta eliminação de dióxido de carbono, entende-se por insuficiência respiratória falha(s) neste processo.

Tais falhas podem ocorrer tanto na ventilação propriamente dita como no controle neural da mesma. Podem ainda envolver a difusão e/ou perfusão. Não raro, mais de uma etapa encontra-se comprometida.

Classicamente, a insuficiência respiratória divide-se em síndromes obstrutivas e restritivas. As síndromes restritivas, por sua vez, subdividem-se em intrínsecas e extrínsecas.

As doenças neuromusculares são exemplos raros de insuficiência respiratória restritiva extrínseca, isto é, os pulmões são primariamente normais. A limitação é dada pela incapacidade de os músculos respiratórios exercerem sua adequada função de "fole torácico". A insuficiência respiratória gerada por esta classe de doenças é, portanto, do tipo ventilatório.

As doenças neuromusculares diferem enormemente entre si, tanto no início do comprometimento respiratório, quanto na intensidade e evolução $(1,2,3)$.

As distrofias musculares têm caráter progressivo e a idade de início do comprometimento da musculatura varia largamente entre os diferentes tipos de distrofias musculares e miopatias - por volta dos 20 anos na Distrofia de Duchenne e 40 na distrofia escapulo-umeral. Como agravante à disfunção das fibras musculares, até $80 \%$ dos pacientes podem apresentar cifoescoliose associada, o que diminui a complacência da parede torácica.

A instalação da insuficiência respiratória nos casos de Esclerose Lateral Amiotrófica caracteriza fase avançada da doença e a progressão é geralmente rápida a partir de então.

A Miastenia Gravis tem caráter auto-imune, com a presença de anticorpos contra receptores de acetilcolina na junção neuro muscular. Especial atenção deve ser dada ao 
emprego de bloqueadores neuromusculares durante anestesia geral em pacientes portadores da doença.

Este tópico será abordado em detalhes em outra exposição.

A Esclerose Múltipla, neuropatia desmielinizante, caracteriza-se por alternância de surtos de atividade e remissão. Desta forma, o suporte ventilatório mecânico pode fazer parte do tratamento de suporte durante a evolução natural da doença mais precocemente que na ELA.

A Síndrome de Guillain-Barré constitui quadro de poliradiculoneurite aguda, geralmente em caráter ascendente - com envolvimento da musculatura respiratória. Em cinqüenta por cento dos casos há relato de quadro infeccioso respiratório ou gastointestinal precedente às manifestações neurológicas.

$\mathrm{Na}$ Doença de Parkinson, a depleção dopaminérgica desencadeia movimentos involuntários, tremor de repouso, perda da mímica facial e rigidez de extremidades (tipo roda denteada). O surgimento de franca insuficiência respiratória é raro. Todavia existe grande tendência a aspiração e, conseqüentemente, surgimento de pneumonias. A apnéia obstrutiva do sono é outro evento bastante comum nestes pacientes.

O comprometimento respiratório no Acidente Vascular Encefálico depende do local acometido. No entanto, o mal-funcionamento da musculatura de vias aéreas superiores é frequiente, levando também a episódios de aspiração. Envolvimento do tronco encefálico geralmente necessita ventilação mecânica controlada precoce, em razão do acometimento do centro respiratório.

De forma análoga, o nível da lesão no traumatismo raqui-medular determina o grau de insuficiência respiratória. Tais pacientes mantêm a competência do centro respiratório e normalidade - ou quase normalidade - de complacências pulmonar, de parede torácica e abdominal.

Tendo em vista o maior risco de aspiração e necessidade de VM pós-operatória, a técnica de anestesia regional deve ser preferida sempre que possível (4). Bloqueios espinhais todavia não devem envolver níveis acima de T10, com o objetivo de não impor redução adicional à função da musculatura respiratória.

As técnicas infra-claviculares são melhor opção que as vias interescalênica e perivascular subclávia para bloqueios do plexo braquial, por não determinarem bloqueio frênico. 
A ventilação mecânica controlada deve ser empregada nos casos de anestesia geral, objetivando a otimização das trocas gasosas. A redução da capacidade residual funcional e tendência ao desenvolvimento de atelectasias, complicações próprias da anestesia, podem ter seu impacto minimizado com o emprego de pressão positiva ao final da expiração (PEEP) e frações inspiradas baixas de oxigênio.

O comprometimento da expansibilidade torácica e a limitada capacidade de tosse são os principais determinantes da necessidade de suporte ventilatório mecânico no período pósoperatório.

\section{Referências}

1.Unterborn JN, Hill NS. Options for mechanical ventilation in neuromuscular diseases. Clin Chest Med 1994; 15(4): 765-81.

2. Dierdorf SF. Rare co-existing diseases. In: Barash PG, Cullen BF, Stoelting RK (eds.) - Clinical Anesthesia. Philadelphia: JB Lippincott Company, 1989, 439-58.

3. Ward NS, Hill NS. Pulmonary function testing in neuromuscular disease. Clin Chest Med 2001; 22(4):769-781.

4. Stoelting RK, Dierdorf SF. Chapter 15: Restrictive Lung Disease. In: Anesthesia and Co-Existing Disease, $4^{\text {th }}$. Ed., Philadelphia: Churchill Livingstone, 2002. 